\title{
The clinical usefulness of cell-free DNA screening in pregnancies with a nuchal translucency between 95th and 99th percentile
}

\author{
hyunmi Lee ${ }^{1}$, You Jung Han ${ }^{2}$, Hyun-Mee Ryu ${ }^{3}$, Soo Hyun $\mathrm{Kim}^{2}$, Moon Young Kim², Hye \\ Yeon Boo ${ }^{1}$, Hee Young Cho ${ }^{3}$, Mi-Young Lee ${ }^{4}$, JinHoon Chung ${ }^{4}$, Seung Mi Lee ${ }^{5}$, Soo-young \\ $\mathrm{Oh}^{6}$, Joon Ho Lee ${ }^{7}$, Geum Joon Cho ${ }^{8}$, Han-Sung Kwon ${ }^{9}$, Byoung Jae Kim ${ }^{10}$, Mi Hye \\ Park $^{11}$, and Hyun-Sun Ko ${ }^{12}$ \\ ${ }^{1} \mathrm{CHA}$ Ilsan Medical center \\ ${ }^{2}$ CHA Gangnam Medical Center \\ ${ }^{3} \mathrm{CHA}$ Bundang Medical Center \\ ${ }^{4}$ Asan Medical Center \\ ${ }^{5}$ Seoul National University College of Medicine \\ ${ }^{6}$ Samsung Medical Center, Sungkyunkwan University School of Medicine, Seoul \\ ${ }^{7}$ Yonsei University College of Medicine Department of Gynecology and Obstetrics \\ ${ }^{8}$ Korea University College of Medicine \\ ${ }^{9}$ Konkuk University School of Medicine \\ ${ }^{10}$ Seoul National University Seoul Metropolitan Government Boramae Medical Center \\ ${ }^{11}$ Ewha Womans University \\ ${ }^{12}$ Catholic University of Korea College of Medicine
}

August 28, 2020

\begin{abstract}
Objective: Evaluate the clinical usefulness of cell-free DNA screening (cfDNA screening) in pregnancies with nuchal translucency (NT) between 95th and 99th percentile. Design: Subgroup analysis of a multicenter prospective cohort study Setting: 12 different secondary and tertiary health care institutions in Korea Sample: 7,547 singleton pregnant women with NT between 95th and 99th percentile Methods: All participants were provided with information about aneuploidy screening or diagnostic testing and selected the first tier test after NT assessment. The first tier test included maternal serum screening tests (MSS), cfDNA screening and invasive test (IT). Main outcome measures: First-tier test preference and chromosomal abnormalities in pregnancies with NT between 95th and 99th percentile Results: A total of 7,547 singleton pregnant women were enrolled and 6,717 cases with known pregnancy outcomes were analyzed. Among these, 89 (1.3\%) cases showed NT between 95th and 99th percentile. As the first-tier test, $47(52.8 \%)$ cases chose cfDNA screening, 33 (37.1\%) cases selected IT, and nine (10.1\%) cases underwent MSS. Chromosomal abnormalities were found in five cases (5.6\%), including four cases with trisomy 21 (T21) and one with a balanced translocation. No significant chromosomal abnormalities undetected by cfDNA screening were noted in pregnancies with NT between 95th and 99th percentile. Conclusion: cfDNA screening in pregnancies with NT between 95th and 99th percentile may be considered as an acceptable alternative to invasive test for women intending to avoid the risk of miscarriage.
\end{abstract}

\section{Introduction}

In 1997, Lo et al. discovered that cell-free fetal DNA (cffDNA) found in maternal plasma was a potential material for fetal aneuploidy analysis [1]. With the development of next-generation sequencing technologies, 
cell-free DNA screening (cfDNA screening) using cffDNA was clinically available in the United States since 2011 and in Korea since 2016. Since cfDNA screening has a sensitivity higher than $99 \%$ with a false-positive rate of less than $0.1 \%$ for detecting T21 [2-3], its performance is better than that of traditional aneuploidy screening tests. The clinical implementation of cfDNA screening has rapidly altered prenatal screening strategy and the timing of prenatal screening has shifted to earlier gestational weeks.

Nuchal translucency (NT) is an important parameter for first trimester aneuploidy screening. The association of increased nuchal translucency (INT) and chromosomal abnormalities was first known in 1992 [4]. INT is associated with adverse pregnancy outcomes such as fetal cardiac defects, miscarriage, and low birth weight, as well as chromosomal abnormalities [5-7]. However, the significance of NT measurements for aneuploidy screening has declined since the introduction of cfDNA screening. The American College of Obstetricians and Gynecologists (ACOG) and the Society for Maternal-Fetal Medicine (SMFM) (2016) guidelines recommend cfDNA screening or diagnostic tests when NT is greater than $3 \mathrm{~mm}$ or more than $99^{\text {th }}$ percentile if there is no structural abnormality of the fetus. However, it is doubtful whether a diagnostic test is needed in cases with NT between $95^{\text {th }}$ and $99^{\text {th }}$ percentile.

The purpose of this study was to evaluate the clinical usefulness of cfDNA screening in cases with NT between $95^{\text {th }}$ and $99^{\text {th }}$ percentile

\section{Materials and Methods}

\section{Participants}

This study is a subgroup analysis of a multi-center prospective cohort designed to investigate the costeffectiveness of various prenatal test strategies after the introduction of cfDNA screening. The protocol was published prior to the analysis of this study [8]. In brief, the prospective cohort study was performed in 12 different secondary and tertiary health care institutions between June 2016 and October 2018. Singleton pregnant women who underwent NT ultrasound examinations were included and counseled regarding fetal aneuploidy screening or diagnostic test before 24 gestational weeks. The cases with unknown pregnancy outcomes were excluded in our study.

NT measurement

NT ultrasound was performed by physicians between 11 and 14 gestational weeks (fetal crown-rump length (CRL) between $45 \mathrm{~mm}$ and $84 \mathrm{~mm}$ ) in each institution. Fetal NT was measured according to the protocol recommended by Fetal Medicine Foundation [9]. Increased NT was diagnosed as $95^{\text {th }}$ percentile or more [3]. The $99^{\text {th }}$ percentile was defined as NT [?] $3.5 \mathrm{~mm}$ for all gestational ages, while the $95^{\text {th }}$ percentile was adjusted for gestational age [10].

Aneuploidy screening and diagnostic tests

All pregnant women were provided with information about aneuploidy screening or diagnostic tests. Basic information included the limitations, test performance and difference between screening and diagnostic test. The screening tests included MSS and cfDNA screening. MSS included combined dual, triple, quad, integrated and sequential tests. cfDNA screening was analyzed for trisomies $21,18,13$. The diagnostic tests included chorionic villus sampling and amniocentesis for conventional karyotyping. Prental chromosomal microarray has not been used clinically in Korea during this study period. The cfDNA screening or diagnostic test was recommended when NT was more than $3 \mathrm{~mm}$ or $95^{\text {th }}$ percentile, and the diagnostic test was recommended when fetal structural defects were observed on ultrasound according to the ACOG guideline [2]. After counseling, participants selected the first tier test. Based on the first-tier test, we divided all the participants into three groups: MSS, cfDNA screening, and IT. When the screening test showed a high risk result, the participants were counseled about further evaluation. In addition, participants were offered detailed, high-resolution ultrasound examinations in the second trimester.

Newborn outcomes 
Newborn outcomes were determined by physical examination at birth or genetic testing. A newborn with normal physical examination was considered to be euploid or normal in the absence of genetic testing.

Statistical analysis

Statistical analysis was conducted using SAS version 9.4 (SAS Institute, Cary, NC). The Chi-square test and ANOVA were used for the comparison of categorical and continuous variables, respectively. The Tukey test was used for post-hoc testing of ANOVA. Ap value $<0.05$ was considered statistically significant.

\section{Results}

A total of 7,547 singleton pregnant women were enrolled in this study. Of these, $52(0.7 \%)$ were miscarriage before 12 weeks of gestation, $51(0.7 \%)$ were withdraw consent after recruitment in the study and $727(9.6 \%)$ were lost to follow-up. The remaining 6,717 cases were included for analysis. Among these, $89(1.3 \%)$ cases had NT between $95^{\text {th }}$ and $99^{\text {th }}$ percentile. The clinical characteristics of the study population are summarized in Table 1. The mean maternal age, gestational age at NT measurement, and NT value were $34 \pm 4.0$ years, $12.1 \pm 0.7$ weeks, and $3.0 \pm 0.3 \mathrm{~mm}$, respectively. Among the study populations, $47(52.8 \%)$ pregnancies selected the cfDNA screening, $33(37.1 \%)$ pregnancies preferred IT, and $9(10.1 \%)$ pregnancies underwent MSS as the first tier test after NT measurement. The clinical characteristics of the three groups were compared according to the first tier test (Table 1). The mean maternal age was $31.8 \pm 3.8$ years in the MSS group, $33.8 \pm 3.8$ years in the cfDNA screening group, and $34.9 \pm 4.1$ years in the IT group. The mean value of NT measurement was $3.0 \pm 0.2 \mathrm{~mm}$ in the MSS group, $2.9 \pm 0.3 \mathrm{~mm}$ in cfDNA screening group, and $3.1 \pm 0.3 \mathrm{~mm}$ in the IT group. There were no differences in maternal age and NT value between the three groups $(p=0.096,0.084)$, respectively. Comparing the patient's choice based on NT value, the cfDNA screening was selected the most $(28,66.7 \%)$ in patients with NT between $95^{\text {th }}$ percentile and $3 \mathrm{~mm}$. IT was selected the most $(24,51.1 \%)$ in patients with NT between 3.0 and $3.5 \mathrm{~mm}$ (Table 2).

Chromosomal abnormalities were diagnosed in five cases (5.6\%) including four cases with trisomy 21 and one case with balanced translocation. NT value was $3.0 \mathrm{~mm}$ or more in all cases. Three cases showed a high risk for trisomy 21 in cfDNA screening (one fetus with hypoplastic nasal bone on first-trimester ultrasound), and IT confirmed the concordant results in all cases. Two cases selected IT as the first tier test, and the results showed trisomy 21 and balanced translocation. One case with balanced translocation showed normal ultrasound findings and was delivered at term and phenotypically normal (Figure 1). No significant chromosomal abnormalities undetected by cfDNA screening were noted in pregnancies with NT between $95^{\text {th }}$ and $99^{\text {th }}$ percentile. Abnormal ultrasound findings at the NT measurement were detected in five cases $(5.6 \%)$ (Table 3). The abnormalities consisted of three cases of cystic hygroma, one case of multiple structural anomalies including cystic hygroma, and another case of hypoplastic nasal bone. Two cases showing multiple structural anomalies and hypoplastic nasal bone were miscarriages before 20weeks of gestation. The one case with cystic hygroma showed hydronephrosis in the second trimester ultrasound, and a normal baby was delivered at term. The remaining two cases with cystic hygroma showed normal ultrasound finding at second trimester, and were normal babies. Detailed, high-resolution ultrasound examination during the second trimester was performed in 79 pregnancies, except when pregnancy was terminated or ended in miscarriage. Abnormal ultrasound findings were noted in eight cases (Table 3). The major structural anomalies included two cases with congenital heart disease. In two cases, IT was followed by detailed, high-resolution ultrasound examination, and the karyotyping result was normal. Soft markers were identified in the remaining six cases including three cases of increased nuchal fold thickness (NFT), two cases of pyelectasis, and one case of echogenic bowel. Five cases showed a low risk with cfDNA screening, and all of them were healthy babies. In one case with increased NFT, IT performed in the first trimester showed normal results.

\section{Discussion}

This study demonstrated that cfDNA screening was preferred and useful test in pregnancies with NT between $95^{\text {th }}$ and $99^{\text {th }}$ percentile. After the pregnant women with NT between $95^{\text {th }}$ and $99^{\text {th }}$ percentile were informed according to the ACOG guideline [2], cfDNA screening (52.8\%) as a first tier test was preferred over IT (37.1\%). The SAFE 21 Study Group explored the pregnant women's attitude toward IT and cfDNA screening 
following positive combined screening [11]. As a result, women with higher NT were more likely to prefer IT, but old age ([?]35 years) did not affect the preference for IT [12]. In our cohort, there was no difference in the choice of first-tier test according to the NT value $(P=0.084)$. However, there was a difference in the test preferences according to the NT value range. While pregnancies with NT between $95^{\text {th }}$ percentile and $3 \mathrm{~mm}$ preferred cfDNA screening $(66.7 \%)$, IT $(51.1 \%)$ was the most preferred in pregnancies with NT between $3 \mathrm{~mm}$ and $3.5 \mathrm{~mm}$. Analysis of the test preferences based on maternal age showed no difference in cfDNA screening selection between [?]35 years and $<35$ years $(48.9 \%$ vs. $51.1 \%, P=0.481)$. Our study found that the NT value range rather than advanced maternal age([?]35 years) affected the patient's choice of the first tier test.

As is well known, INT is associated with chromosomal abnormalities [3, 13, 14], and previous studies reported approximately 3.7-7.1\% incidence of chromosomal abnormalities in fetuses with INT [3, 15]. ACOG and SMFM recommend cfDNA screening or diagnostic testing for women with NT[?]3.0mm or $99^{\text {th }}$ percentile [16]. However, cfDNA screening has limited value for detecting chromosomal abnormalities in a fetus with INT. Several studies reported that the proportion of T21 was decreased as the thickness of NT increased [3, 15, 17]. Chromosomal abnormalities undetected by cfDNA screening were reported in $2 \%-10 \%$ of fetuses with NT[?] $99^{\text {th }}$ percentile $[18-22]$. Thus, diagnostic testing rather than cfDNA screening should be considered as the first-tier test in pregnancies with NT[?]3.5mm. However, it is questionable whether this strategy should be applicable to pregnancies with NT between $95^{\text {th }}$ and $99^{\text {th }}$ percentile. Nicolaides et al. demonstrated that the incidence of T21 was $66.1 \%$ of chromosomal abnormalities in fetuses with NT between $95^{\text {th }}$ percentile and $3.5 \mathrm{~mm}$ [15]. In this study, chromosomal abnormalities were $5.6 \%$ and T21 accounted for $80 \%$ of chromosomal abnormalities. Berger et al. reported that rare aneuploidies undetectable by cfDNA screening were found in $0.8 \%$ of pregnancies with NT between $3 \mathrm{~mm}$ and $3.5 \mathrm{~mm}$ [12]. A large cohort study showed chromosomal abnormalities undetected by cfDNA screening but detected by classic karyotyping in $0.6 \%$ of fetuses with NT between $95^{\text {th }}$ and $99^{\text {th }}$ percentile [21]. Additionally, a recent meta-analysis reported accuracy of cfDNA screening in detecting $>99 \%$ of fetuses with T21, $98 \%$ of T18 and $99 \%$ of T13 with a combined false positive rate of $0.13 \%$ [23]. Therefore, the low risk of cfDNA screening was acceptable to pregnant women with NT between $95^{\text {th }}$ and $99^{\text {th }}$ percentile.

In the previous study, the incidence of major fetal abnormalities was $2.5 \%$ in a chromosomally normal fetus with NT between $95^{\text {th }}$ and $99^{\text {th }}$ percentile [21]. Ghiet et al. reported that the prevalence of major cardiac defects in the fetus with NT between $95^{\text {th }}$ and $99^{\text {th }}$ percentile was $2.5 \%$ [24]. Atzei et al. reporteda $2 \%$ prevalence of cardiac defects in fetuses with NT between $95^{\text {th }}$ and $99^{\text {th }}$ percentile, and was similar to that of patients with a family history of cardiac defects and diabetes mellitus [25]. In our study, the prevalence of major fetal structural anomalies was $2.5 \%$, and all cases showed ventricular septal defect. Therefore, pregnant women with NT between $95^{\text {th }}$ and $99^{\text {th }}$ percentile should be recommended to undergo detailed, high-resolution ultrasound examinations in the second trimester.

The weakness of our study is the small number of pregnancies with NT between $95^{\text {th }}$ and $99^{\text {th }}$ percentile. The incidence of NT between $95^{\text {th }}$ and $99^{\text {th }}$ percentile was about $1.3 \%$ in our study, lower than $4 \%$ in the previous study by Souka et al. [3]. We excluded the cases with unknown pregnancy outcomes, which could have led to a lower incidence of INT and selection bias. Also, cfDNA screening targeted trisomies 21,18,13, which was relatively not difficult to identify chromosomal abnormalities morphologically, because we defined newborn babies with normal physical examination as euploidy. The inclusion of them with undiagnosed chromosomal abnormalities might bias. However, the main strength of our study is the prospective design in a large multicenter cohort, and it was possible to find out which test pregnant women with NT between $95^{\text {th }}$ and $99^{\text {th }}$ percentile preferred in the clinical field.

\section{Conclusion}

In conclusion, the low risk result of cfDNA screening is acceptable for patients with NT between $95^{\text {th }}$ and $99^{\text {th }}$ percentile. Therefore, cfDNA screening in pregnant women with NT between $95^{\text {th }}$ and $99^{\text {th }}$ percentile may be considered as an acceptable alternative to invasive test for women intending to avoid the risk of miscarriage, although the procedure related risks of miscarriage after CVS and amniocentesis are low (0.1\%) 
$[26]$.

\section{DISCLOSURE OF INTEREST}

The author(s) declared no potential conflicts of interest with respect to the research, authorship, and/or publication of this article.

\section{CONTRIBUYION TO AUTHORSHIP}

YJH, HMR and JHC designed this study. SHK, MYK, HYB, HYC, MYL, SML, SYO, JHL, GJC, HSK, BJK, MHP and HSK contributed to the acquisition of data. HML contributed to analysis of data. YJH and JHC reviewed articles. HML wrote the initial manuscript. All authors contributed to the writing of the final manuscript.

\section{DETAILS OF ETHICS APPROVAL}

The study was approved by the institutional review boards (CGH-IRB-2016-13; Approval date, May 12, 2016).

\section{FUNDING}

This study was supported by the National Health Clinical Research Program Grant from the Korea Health Industry Development Institute (KHIDI), Republic of Korea (HC15C1336).

\section{References}

1. Kim MH, Park SH, Cho HJ, Choi JS, Kim JO, Ahn HK, Shin JY. Kim MY, Yang JH. Threshold of nuchal translucency for the detection of chromosomal aberration: comparison of different cutoffs. J Korean Med Sci 2006;21:11-14.

2. Committee Opinion No.640: Cell-free DNA screening for fetal aneuploidy. Obstet Gynecol 2015;126:e31-37.

3. Souka AP, Von Kaisenberg CS, Hyett JA, Sonek JD, Nicolaides KH. Increased nuchal translucency with normal karyotype. Am J Obstet Gynecol 2005;192:1005-1021.

4. Nicolaides KH, Azar G, Byrne D, Mansur C, Marks K. Fetal nuchal translucency: ultrasound screening for chromosomal defects in first trimester of pregnancy. BMJ 1992;304:867-869.

5. Bekker MN, Haak MC, Rekoert-Hollander M, Twisk J, Van Vugt JM. Increased nuchal translucency and distended jugular lymphatic sacs on first-trimester ultrasound. Ultrasound Obstet Gynecol 2005;25:239-245.

6. Nicolaides KH. First-trimester screening for chromosomal abnormalities. Semin Perinatol 2005;29:190194.

7. Bilardo CM, Pajkrt E, de Graaf I, Mol BW, Bleker OP. Outcome of fetuses with enlarged nuchaltranslucency and normal karyotype. Ultrasound Obstet Gynecol 1998;11:401-406.

8. Kim SY, Lee SM, Jun JK, Han YJ, Kim MH, Shim JY, Lee MY, Oh SY, Lee J. Kim SH, Cha DH, Cho GJ, Kwon HS, Kim BJ, Park MH, Cho HY, Ko HS, Ahn J, Ryu HM. Prospective observations study protocol to investigate cost-effectiveness of various prenatal test strategies after the introduction of noninvasive prenatal testing. BMC Pregnancy Childbirth 2018;18:307.

9. Fetal Medicine Foundation. https://fetalmedicine.org/nuchal-translucency-scan/[12September 2010].

10. Wright D, Kagan KO, Molina FS, Gazzoni A, Nicolaides KH. A mixture model of nuchal translucency thickness in screening for chromosomal defects. Ultrasound Obstet Gynecol 2008; 31:376-383.

11. Seror V, L'Haridon O, Bussieres L, Malan V, Fries N, Vekemans M, Salomon LJ, Ville Y; SAFE 21 Study Group.Women's Attitudes Toward Invasive and Noninvasive Testing When Facing a High Risk of Fetal Down Syndrome. JAMA Netw Open 2019;2:e191062.

12. Berger VK, Norton ME, Sparks TN, Flessel M, Baer RJ, Currier RJ. The utility of nuchal translucency ultrasound in identifying rare chromosomal abnormalities not detectable by cell-free DNA screening. Prenat Diagn 2020;40:185-190. 
13. Nicolaides KH. Nuchal translucency and other first-trimestersonographic markers of chromosomal abnormalities. Am J Obstet Gynecol 2004;191:45-67.

14. Souka AP, Snijders RJ, Novakov A, Soares W, Nicolaides KH. Defects and syndromes in chromosomally normal fetuses withincreased nuchal translucency thickness at 10-14 weeks ofgestation. Ultrasound Obstet Gynecol 1998;11:391-400.

15. Kagan KO, Avgidou K, Molina FS, Gajewska K, Nicolaides KH. Relation between increased fetal nuchal translucency thickness and chromosomal defects. Obstet Gynecol 2006;107: 6-10.

16. ACOG Practice Bulletin No. 163: Screening for fetal aneuploidy. Obstet Gynecol 2016; 127:e123-137.

17. Shakoor S, Dileep D, Tirmizi S, Rashid S, Amin Y, Munim S.Increased nuchal translucency and adverse pregnancy outcomes. J Matern Fetal Neonatal Med 2017;30:1760-1763.

18. Lichtenbelt KD, Diemel BD, Koster MP, Manten GT, Siljee J, Schuring-Blom GH, Page-Christiaens GC. Detection of fetal chromosomal anomalies: does nuchal translucency measurement have added value in the era of non-invasive prenatal testing? Prenat Diagn 2015; 35:663-668.

19. Srebniak MI, de Wit MC, Diderich KE, Govaerts LC, Joosten M, Knapen MF,Bos MJ, Looye-Bruinsma GA, Koningen M, Go AT, Galjaard RJ, Van Opstal D. Enlarged NT ([?]3.5 mm) in the first trimester - not all chromosome aberrations can be detected by NIPT. Mol Cytogenet 2016;9:69.

20. Khalil A, Mahmoodian N, Kulkarni A, Homfray T, Papageorghiou A, Bhide A, Thilaganathan B. Estimation of detection rates of aneuploidy in high-risk pregnancy using an approach based on nuchal translucency and non-invasive prenatal testing: a cohort study. Fetal Diagn Ther 2015;38:254-261.

21. Bardi F, Bosschieter PFN, Verheij JBGM, Go ATJI, Haak MC, Bekker MN, Sikkel E, Coumans $\mathrm{ABC}$, Pajkrt E, Bilardo CM. Is there still a role for nuchal translucency measurement in the changing paradigm of the changing paradigm of first trimester screening? Prenat Diagn 2020;40:197-205.

22. Syngelaki A, Pergament E, Homfray T, Akolekar R, Nicolaides KH. Replacing the combined test by cell-free DNA testing in screening for trisomies 21, 18 and 13: impact on the diagnosis of other chromosomal abnormalities. Fetal Diagn Ther 2014;35:174-84.

23. Gil MM, Accurti V, Santacruz B, Plana MN, Nicolaides KH.Analysis of cell-free DNA in maternal blood in screening for aneuploidies: updated meta-analysis. Ultrasound Obstet Gynecol 2017;50:302-314.

24. Ghi T, Huggon IC, Zosmer N, Nicolaides KH. Incidence of major structural cardiac defects associated with increased nuchal translucency but normal karyotype. Ultrasound Obstet Gynecol 2001;18:610-614.

25. Atzei A, Gajewska K, Huggon IC, Allan L, Nicolaides KH. Relationship between nuchal translucency thickness and prevalence of major cardiac defects in fetuses with normal karyotype. Ultrasound Obstet Gynecol 2005;26:154-157.

26. LJ Salomon, A Sotiriadis, CB Wulff, A Odibo, R Akolekar. Risk of miscarriage following amniocentesis or chorionic villus sampling: systematic review of literature and updated meta-analysis. Ultrasound Obstet Gynecol 2019;54:442-451.

\section{Hosted file}

table_BJOG.docx available at https://authorea.com/users/353988/articles/477697-the-clinicalusefulness-of-cell-free-dna-screening-in-pregnancies-with-a-nuchal-translucency-between95th-and-99th-percentile 